\title{
The Cytocompatibility of Genipin-Crosslinked Silk Fibroin Films
}

\author{
Lingshuang Wang ${ }^{1}$, Yiyu Wang ${ }^{1,2}, J_{i n g} \mathrm{Qu}^{1}$, Yongpei $\mathrm{Hu}^{1}$, Renchuan You ${ }^{1}$, Mingzhong $\mathrm{Li}^{1 *}$ \\ ${ }^{1}$ National Engineering Laboratory for Modern Silk, College of Textile and Clothing Engineering, Soochow University, Suzhou, \\ China; ${ }^{2}$ Life Science Technology School, Hubei Engineering University, Xiaogan, China. \\ Email: ${ }^{*}$ mzli@suda.edu.cn
}

Received April $1^{\text {st }}, 2013$; revised May $24^{\text {th }}, 2013$; accepted June $8^{\text {th }}, 2013$

Copyright (C) 2013 Lingshuang Wang et al. This is an open access article distributed under the Creative Commons Attribution License, which permits unrestricted use, distribution, and reproduction in any medium, provided the original work is properly cited.

\begin{abstract}
There is an increasing demand for crosslinking methods of silk fibroin (SF) scaffolds in biomedical applications that could maintain the biocompatibility, bioactivity as well as improve the water resistance and mechanical properties of SF materials. In this study, SF was crosslinked effectively with genipin which is a naturally occurring iridoid glucoside and the crosslinking mechanism was investigated through FTIR and amino acid analysis. The results showed that genipin could react with the $-\mathrm{NH}_{2}$ groups on the side chains of SF macromolecules and to form inter- and intra-molecular covalent bonds, and improved the stability of SF materials significantly. In vitro, the performances of genipin-crosslinked SF films were assessed by seeding L929 cells and compared with ethanol-processed SF films, glutaraldehyde and polyethylene glycol diglycidyl ether crosslinked ones. The genipin-crosslinked SF films showed a similar affinity to cells as ethanol-processed ones, and a higher bioactivity in promoting cell growth and proliferation, inhibition of cell apoptosis, and maintenance of normal cell cycle compared with glutaraldehyde and polyethylene glycol diglycidyl ether crosslinked SF films. These features, combined with the decrease of brittleness of SF films crosslinked with chemical methods, substantiated genipin as an effective and biocompatible agent for the manufacturing of bioactive SF materials which used as tissue engineering scaffolds and drug delivery carriers.
\end{abstract}

Keywords: Silk Fibroin; Films; Genipin; Cytocompatibility

\section{Introduction}

The unique chemical and mechanical properties, impressive cytocompatibility and bioactivity of silk fibroin (SF) materials make silk a popular starting material for tissue engineering scaffolds used in skin, blood vessel, bone, ligament, cornea and nerve regeneration [1-4].

An SF material prepared with different surface structure could induce the proliferation of corneal cells and increase the cells' expression of extracellular matrix [5]. By altering the treatment method, the surface structure of SF membrane could be changed to guide cell adhesion, migration, and distribution [6]. The SF materials prepared from SF solution which is obtained after dissolving the natural SF fibers are usually water dissoluble and must be treated to stabilize the SF materials against water before they can be used in tissue engineering. A variety of treatment methods have been established to process SF materials. Physical methods include high-temperature

${ }^{*}$ Corresponding author. processing, methanol/ethanol treatment and ultraviolet radiation [7]. These methods could improve the material's water resistance but may have a negative effect on rigidity and brittleness of the scaffold in the dry state $[8$, 9]. The common chemical crosslinking agents used in stabilizing SF materials include glutaraldehyde [10,11], carbodiimide [12], and polyethylene glycol diglycidyl ether (PEGDE) [13]. The interaction between the materials and the host cells is a key factor in determining the biocompatibility of a material, while the choice of cross-linking agent makes a difference in the cytocompatibility of the material [14]. There is an increasing demand for a nontoxic crosslinking method of SF in biomedical applications that could maintain the biocompatibility, bioactivity as well as improving the water resistance and mechanical properties of SF materials.

Genipin is an aglycone derivative from an iridoid glycoside called geniposide extracted from Gardenia fruit, obtained via enzymatic hydrolysis with $\beta$-glucosidase, which could display desirable characteristics as a natu- 
rally occurring crosslinking agent [15]. Genipin is known to react rapidly with amino acid or proteins to form blue pigments, which are used in herbal medicine and the fabrication of food dyes $[16,17]$. Genipin also exhibits excellent cytocompatibility and tissue compatibility in fixing collagen, gelatin, chitosan, and other tissue engineering scaffolds for bone, cartilage, nerve repair, etc. [1824].

In this work, we present a new stable, biocompatible and bioactive SF film which used genipin as a crosslinking agent, and the crosslinking mechanism was analyzed. Glutaraldehyde and PEGDE crosslinked SF films and an ethanol-processed SF film were also prepared as control samples. These films were used as a support to culture L929 cells, and the films' cytocompatibility were compared by measuring cell viability, metabolic activity, cell cycle, and apoptosis.

\section{Materials and Methods}

\subsection{Preparation of SF Films}

Bombyx mori raw silk fibers were purchased from Zhejiang the Second Silk Co. Ltd. (Huzhou, China). Silk fibroin solution was prepared using a chemical degumming method before dissolution and dialysis. Raw silk fibers were degummed three times in boiled $\mathrm{Na}_{2} \mathrm{CO}_{3}$ solution $(0.05 \%)$ for $30 \mathrm{~min}$ and dried in an oven at $60^{\circ} \mathrm{C} \pm$ $2^{\circ} \mathrm{C}$ after being rinsed thoroughly. The extracted SF fiber was then dissolved in a ternary solvent of $\mathrm{CaCl}_{2}$ :

$\mathrm{CH}_{3} \mathrm{CH}_{2} \mathrm{OH}: \mathrm{H}_{2} \mathrm{O}(1: 2: 8)$ at $72^{\circ} \mathrm{C} \pm 2^{\circ} \mathrm{C}$ for $1 \mathrm{~h}$. Silk fibroin solution was obtained after dialysis in deionized water for 4 days. The pure SF film was obtained after pouring SF solution into a mold, which was then dried in an oven at $60^{\circ} \mathrm{C} \pm 2^{\circ} \mathrm{C}$, the film became insoluble after treatment with $75 \%$ ethanol for $2 \mathrm{~h}$. The genipin-crosslinked film was prepared by dissolving genipin (Sigma) in the SF solution with stirring at $37^{\circ} \mathrm{C} \pm 1^{\circ} \mathrm{C}$ for $12 \mathrm{~h}$. This mixture was then poured into a mold and dried in an oven at $60^{\circ} \mathrm{C} \pm 2^{\circ} \mathrm{C}$ for $2 \mathrm{~h}$. The glutaraldehyde-crosslinked silk film and PEGDE-crosslinked film were obtained using similar methods. Briefly, the SF solution was mixed directly with glutaraldehyde (Sigma, $1 \%$ of the SF weight) or PEGDE (Sigma, 30\% of the SF weight) and poured into a mold, which was then dried in an oven at $60^{\circ} \mathrm{C} \pm 2^{\circ} \mathrm{C}$ and stewing for $24 \mathrm{~h}$. The molds used to prepare the films were $35 \mathrm{~mm}$ in length and $10 \mathrm{~mm}$ in width. The thickness of manufactured films was about 40 $\mu \mathrm{m}$.

\subsection{Characteristics of the Genipin-Crosslinked SF Films}

Amino acid analysis, Fourier transform infrared (FTIR) spectroscopy and X-ray diffraction were used to evaluate the characteristics of the genipin-crosslinked silk films.
The films were cut into particles and FTIR spectra were obtained with a Nicolet Avatar-IR 360 spectrometer after preparation of the samples in $\mathrm{KBr}$ pellets. The infrared spectra covering the amide region $\left(1595-1720 \mathrm{~cm}^{-1}\right)$ were analyzed by Opus 5.0 software (Bruker, Germany). The percentage composition of different secondary structures was obtained by peak-differentiation. X-ray diffraction was performed by X'pert-Pro MPD diffractometer, and $\mathrm{CuK} \alpha$ radiation with a wavelength of $1.5406 \AA$ was used. The scanning speed was $2 \% \mathrm{~mm}$. The diffraction intensity curves with $2 \theta$ from $5^{\circ}$ to $45^{\circ}$ were obtained. For the amino acid analysis, the uncrosslinked and genipincrosslinked SF films were prepared by hydrolysis in $6 \mathrm{M}$ $\mathrm{HCl}$ at $110^{\circ} \mathrm{C}$ for $18 \mathrm{~h}$ and an amino acid analyzer (Hitachi model 835 - 50) was used to determine the identity and quantity of amino acids in the hydrolyzed products. Hot-water-solubility tests were also carried following the procedure described previously [25]. Briefly, the uncrosslinked and genipin-crosslinked SF films were immersed into deionized water at $37^{\circ} \mathrm{C} \pm 1{ }^{\circ} \mathrm{C}$ for $24 \mathrm{~h}$ and the weight loss was measured after dried in an oven at $105^{\circ} \mathrm{C}$ $\pm 2^{\circ} \mathrm{C}$.

\subsection{In Vitro Cell Culture}

All the samples were cut into appropriate sizes and irradiated with an exposure dose of $20 \mathrm{kGy}$ by a $\mathrm{Co}^{60}$ irradiator (Institute of Radiation Technique, Soochow University) followed by thorough rinsing in sterilized phosphate buffered saline (PBS) prior to cell seeding. L929 cells supplied by the Department of Medicine in Soochow University were cultured in Dulbecco's modified Eagle's medium (DMEM, Gibco) with $10 \%$ bovine serum albumin (Gibco) and 1\% penicillin/streptomycin (Shanghai Sibas) at $37^{\circ} \mathrm{C}$ in a humidified atmosphere containing 5\% $\mathrm{CO}_{2}$. Cultured L929 cells were then trypsinized and centrifuged at $1000 \mathrm{rpm}$ for $5 \mathrm{~min}$. After discarding the supernatant, the cells were seeded on the membranes at a density of $5 \times 10^{4}$ cells/well in 24-well tissue-culture clusters (JET BIOFIL) covered with different films and incubated in $37^{\circ} \mathrm{C}$ incubator. The culture medium was replaced daily.

\subsection{MTT Assay}

The cellular viability and mitochondrial activity of viable cells on the crosslinked films were determined using a methyl thiazolyl tetrazolium (MTT) cell viability assay. This assay is a quantitative colorimetric assay of mammalian cell survival and cell proliferation. Viable cells with active mitochondria reduce significant amounts of MTT, to form an insoluble dark blue formazan product. The cell-seeded films were incubated and selected for MTT assay on days 1, 3, 5, 7, and 9. The cells were then 
washed with PBS and incubated in media containing MTT $(5 \mathrm{mg} / \mathrm{ml})$ for $4 \mathrm{~h}$; formazan crystals produced by the cells were dissolved in dimethyl sulfoxide (DMSO). The optical density (OD) at $570 \mathrm{~nm}$ of formazan was measured on a Synergy HT (BIO-TEK) microplate reader and the number of viable cells was calculated by converting the $\mathrm{OD}$ values into cell numbers according to a standard calibration curve. Eight MTT assay replicates were performed for each formulation and culture period and the average values were adopted.

\subsection{Cell Metabolism Assay}

The metabolism of L929 cells on the films was measured after culturing for 4,6 , and 8 days by the Coomassie brilliant blue assay. Briefly, a standard calibration curve was prepared using bovine serum albumin (BSA) as a standard solution. Cells seeded on each group of films for 4, 6 and 8 days were then washed with PBS twice, trypsinized, and centrifuged. After discarding the supernatant, $1.2 \mathrm{ml} \mathrm{NaOH}(0.75 \mathrm{~mol} / \mathrm{L})$ was added to each sample and allowed to react for $3 \mathrm{~min}$ at $100^{\circ} \mathrm{C}$. Then $0.1 \mathrm{ml} \mathrm{ly}$ sate was mixed with $5 \mathrm{ml}$ Coomassie brilliant blue dye (Honda biotechnology corporation, Beijing) and left to stand for $10 \mathrm{~min} .2 \mathrm{ml}$ of the mixed medium from each sample were analyzed at $605 \mathrm{~nm}$ in an ultraviolet spectrophotometer (U-3010). Coomassie brilliant blue dye and $100 \mu \mathrm{l}$ cell lysates were used as blank controls.

\subsection{Flow Cytometric Analysis of Cell Death and Apoptosis}

Flow cytometry analysis permits the simultaneous detection of necrosis and apoptosis of cells. Samples of L929 cells cultured on the films for 3 days were digested, collected, and washed in PBS and centrifuged. They were then incubated with $1 \times$ annexin-binding buffer $100,5 \mu 1$ Alexa Fluor 488 Annexin v, and $2 \mu 1$ propidium iodide (PI) solution $(100 \mu \mathrm{g} / \mathrm{ml})$ for $15 \mathrm{~min}$. Cells were analyzed using a flow cytometer (FC500) within $24 \mathrm{~h}$ and a cell column diagram was obtained automatically after analysis of $1 \times 10^{4}$ cells.

\subsection{Cell-Cycle Analysis}

L929 cells were seeded at a density of $1 \times 10^{5}$ cells/well on films within 6-well plates (Biofil). After incubation for 3 days, $2 \mathrm{ml}$ trypsin was added to the samples and then incubated on a shaker at $300 \mathrm{rpm}$ until all cells were detached. The cell suspension was washed with PBS and mixed with $70 \%$ ethanol at $4^{\circ} \mathrm{C}$ overnight. After centrifugation and further washing with PBS, the samples were recentrifuged and resuspended in $1 \mathrm{ml}$ PI solution (50 $\mu \mathrm{g} / \mathrm{ml}$ PI, $0.1 \mathrm{mg} / \mathrm{ml}$ RNAse A). The cell samples were finally incubated for $30 \mathrm{~min}$ before computer analysis.

\subsection{Statistical Analysis}

All data were collected in triplicate and expressed as mean \pm standard deviation. Statistical comparisons were performed using analysis of variance (ANOVA), and differences were considered statistically significant at a probability of $P<0.05$.

\section{Results and Discussion}

\subsection{The Crosslinking Mechanism and Molecular Conformation of SF Films}

Figure 1 shows the FTIR spectra of the uncrosslinked and genipin-crosslinked SF films. New adsorption bands at $887 \mathrm{~cm}^{-1}$ and $1107 \mathrm{~cm}^{-1}$ were clearly appeared after crosslinking with genipin: $1107 \mathrm{~cm}^{-1}$ represents the stretching vibration of $\mathrm{C}-\mathrm{N}$, where the atom $\mathrm{N}$ is the tertiary atom after the lysine reaction with genipin, while $887 \mathrm{~cm}^{-1}$ can be considered as the characteristic adsorption band of the $\mathrm{C}-\mathrm{H}$ stretching vibration region on the heterocyclic ring in the product. Moreover, adsorption band appeared at $1235 \mathrm{~cm}^{-1}$ (amide III) represents a mixed vibration of CO-N and $\mathrm{N}-\mathrm{H}$. This adsorption band and characteristic adsorption bands at $1334 \mathrm{~cm}^{-1}, 1162 \mathrm{~cm}^{-1}$, and $1065 \mathrm{~cm}^{-1}$ decreased after the addition of genipin, owing to the reaction of the $-\mathrm{NH}_{2}$ on the lysine with the genipin.

Figure 2 shows the crosslinking mechanism of genipin-crosslinked SF films. The free amine group in the SF macromolecule initiated a nucleophilic attack on the olefinic carbon at C-3 of genipin, resulting in the opening of the dihydropyran ring and the formation of an aldehyde group. A heterocyclic amine intermediate was formed. Then the genipin-amino-group monomer was formed through the formation of new covalent bonds between the aldehyde group and the secondary amine and the

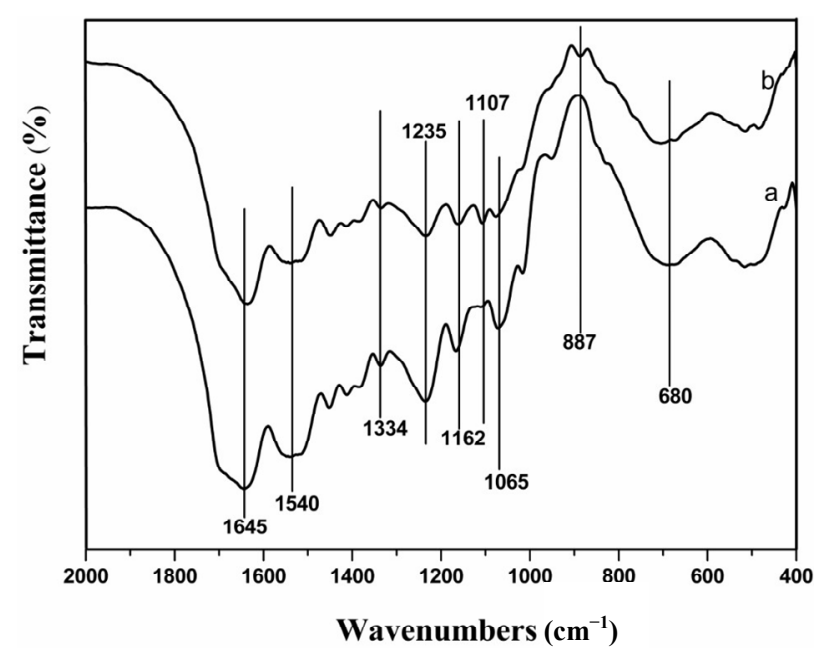

Figure 1. FTIR spectra of (a) uncrosslinked SF film and (b) genipin-crosslinked SF film. 


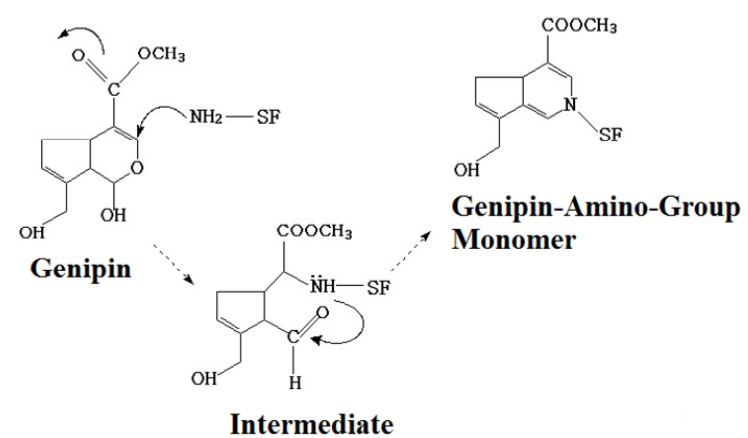

(a)
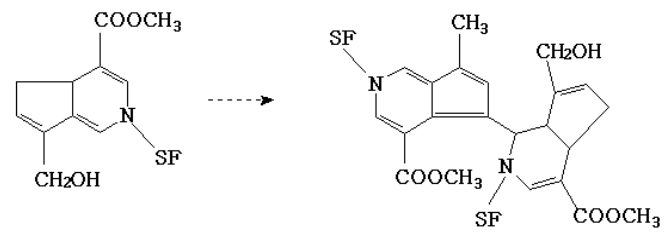

(b)

Figure 2. Crosslinking reaction of SF by genipin: (a) formation of genipin-amino-group monomer; (b) formation of intermolecular chains in SF.

formation of double linkage in the carbon ortho-position (Figure 2 (a)). The blue-pigment polymers were presumably formed through monomer polymerization (Figure 2 (b)). Polymerization occurred among genipin molecules which had already reacted with free amino in SF and then inter-molecular covalent bonds were formed among SF molecules. Polymerization may also occur among genipin molecules prior to undergoing crosslinking with SF. Finally, inter-molecular and intra-molecular cross-links with cyclic structures were formed in the silk fibroin.

Previous studies on the molecular conformation of SF revealed that the $\alpha$-helix usually exhibits characteristic absorption bands at $1650-1655 \mathrm{~cm}^{-1}$ (amide I), 1525 $1540 \mathrm{~cm}^{-1}$ (amide II), $1266 \mathrm{~cm}^{-1}$ (amide III), and 669 $\mathrm{cm}^{-1}$ (amide $\mathrm{V}$ ), while $\beta$-sheets have characteristic bands at $1620-1635 \mathrm{~cm}^{-1}$ (amide I), $1530 \mathrm{~cm}^{-1}$ (amide II), $1230-1235 \mathrm{~cm}^{-1}$ (amide III) and $700 \mathrm{~cm}^{-1}$ (amide V); absorbance bands at $1655-1660 \mathrm{~cm}^{-1}$ (amide I), 1535 $1545 \mathrm{~cm}^{-1}$ (amide II), $1235 \mathrm{~cm}^{-1}$ (amide III), and 650 $\mathrm{cm}^{-1}$ (amide $\mathrm{V}$ ) were assigned to the random coil conformation [26]. Figure 1 showed that the adsorption bands of amide I migrated from about $1645 \mathrm{~cm}^{-1}$ to $1635 \mathrm{~cm}^{-1}$ and the adsorption band of amide $\mathrm{V}$ migrated from about $680 \mathrm{~cm}^{-1}$ to $700 \mathrm{~cm}^{-1}$, indicating that the proportion of $\beta$ sheet increased and that of random coils decreased after genipin crosslinking. The content of $\beta$-sheet increased significantly from about $12.0 \%$ to $24.1 \%$ after genipin crosslinking (Table 1). These results indicated that genipin could play the role of a chemical cross-linker as well as inducing SF molecular formation translates from random coil and/or $\alpha$-helix to $\beta$-sheet.
The main diffractions of $\alpha$-form structure of silk fibroin are at $12.2^{\circ}(\mathrm{d}=7.25 \AA$, medium strong $), 19.7^{\circ}(\mathrm{d}=$ $4.5 \AA$, strong), $24.7^{\circ}(\mathrm{d}=3.60 \AA$, medium $), 28.2^{\circ}(\mathrm{d}=$ $3.16 \AA$, medium); and those of $\beta$-sheet conformation are at $9.1^{\circ}(\mathrm{d}=9.7 \AA$, medium strong $), 18.9^{\circ}(\mathrm{d}=4.69 \AA$, medium strong), $20.7^{\circ}(\mathrm{d}=4.30 \AA$, very strong) and $24.3^{\circ}(\mathrm{d}=3.67 \AA$, medium strong) [27].

The uncrosslinked SF film showed arc-shaped scattering at around $20^{\circ}$ and weak diffraction at around $12.2^{\circ}$ (Figure 3), indicating the aggregation structure was mainly amorphous structure with a little $\alpha$-form structure. The genipin crosslinked SF film showed strong and sharp diffraction at around $20.7^{\circ}$ and weak diffraction at around $24.3^{\circ}$ which demonstrated that the content of $\beta$-sheet conformation increased after genipin crosslinking. These results also showed that genipin could induce the conformational transformation of SF from random coil and/ or $\alpha$-form to $\beta$-sheet which was consistent with FTIR spectroscopy.

\subsection{Amino Acid Composition of SF Films}

The content of lysine and tyrosine in SF decreased from $0.41 \%$ and $11.56 \%$ to $0.18 \%$ and $9.10 \%$ respectively after genipin crosslinking, while the content of other amino acid showed no obvious decrease (Table 2). This result further proved the occurrence of a crosslinking reac-

Table 1. Molecular conformation of SF films derived from deconvoluted amide I regions of the FTIR spectra.

\begin{tabular}{ccccc}
\hline \multirow{2}{*}{ Samples } & \multicolumn{4}{c}{ Conformation content of SF films (\%) } \\
\cline { 2 - 5 } & $\beta$-sheet & random coil & $\alpha$-helix & $\beta$-turn \\
\hline Pure SF film & 12 & 44 & 15 & 29 \\
Genipin-crosslinked SF film & 24 & 36 & 9 & 31 \\
\hline
\end{tabular}

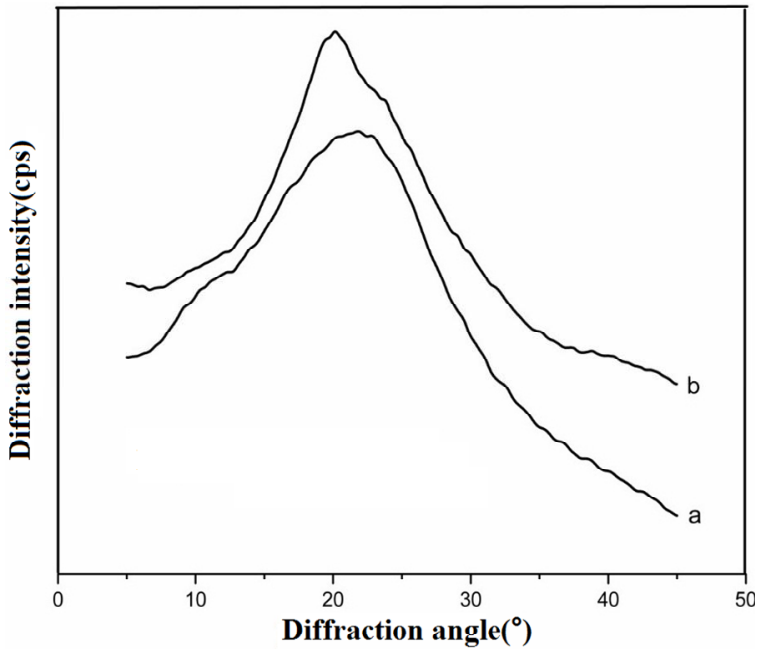

Figure 3. XRD curves of (a) uncross-linked SF film and (b) genipin-crosslinked SF film. 
Table 2. Amino acid composition of uncrosslinked and genipin-crosslinked silk fibroin films (mol.\%).

\begin{tabular}{|c|c|c|}
\hline \multirow{2}{*}{ Amino acid } & \multicolumn{2}{|c|}{ Type of silk films } \\
\hline & Uncrosslinked & Crosslinked \\
\hline Asp & 2.33 & 2.40 \\
\hline Thr & 1.21 & 1.22 \\
\hline Ser & 12.49 & 12.86 \\
\hline Glu & 2.00 & 2.02 \\
\hline Gly & 34.51 & 35.07 \\
\hline Ala & 28.25 & 29.79 \\
\hline Cys & 0.06 & 0.05 \\
\hline Val & 2.94 & 3.07 \\
\hline Met & 0.16 & 0.08 \\
\hline Ile & 0.85 & 0.85 \\
\hline Leu & 0.18 & 0.23 \\
\hline Tyr & 11.56 & 9.10 \\
\hline Phe & 1.08 & 1.15 \\
\hline Lys & 0.41 & 0.18 \\
\hline $\mathrm{NH}_{3}$ & 0.36 & 0.32 \\
\hline His & 0.31 & 0.29 \\
\hline Arg & 0.83 & 0.81 \\
\hline Pro & 0.47 & 0.50 \\
\hline
\end{tabular}

tion, which consumed some of the lysine in the SF macromolecules. Moreover, the results from the hot watersolubility test revealed that after genipin crosslinking, the SF film showed a better water tolerance- the weight loss rate decreased from about $46 \%$ to $12 \%$. This also confirmed that genipin could act effectively as a crosslinking agent for SF.

\subsection{Growth of L929 Cells on SF Films}

After a 3-day culture, seeded L929 cells were able to attach, grow, and multiply on the surfaces of all the films (Figure 4). The cells grew well, in accordance with the close-packed rule, in the form of antennae or scalene triangles on the genipin-crosslinked SF film. The cell numbers were almost the same as the ethanol-treated film. The genipin group and ethanol-treated group retained more cells than either glutaraldehyde or PEGDE group. Some of the cells even showed morphologic changes at the early stage of apoptosis on the PEGDE group: the cells shrank and turned round. Overall, the genipin group displayed higher cell proliferation than the glutaraldehyde and PEGDE groups.
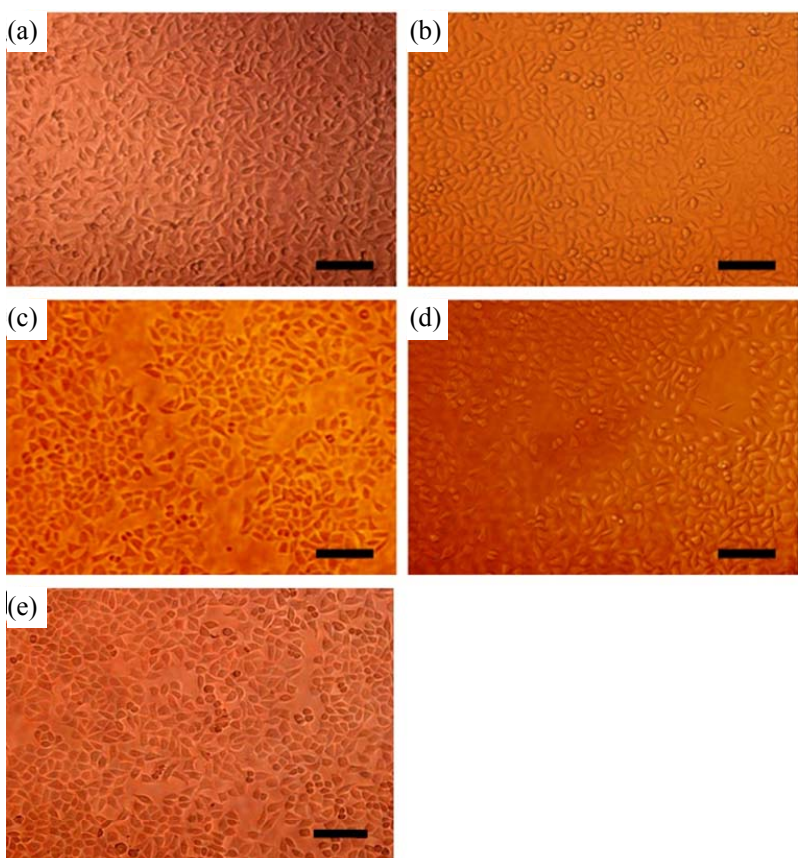

Figure 4. Inverted fluorescence micrographs of L929 cells cultured for 3 days on SF films: (a) genipin-crosslinked, (b) ethanol-processed, (c) glutaraldehyde-crosslinked, (d) PEGDE-crosslinked, (e) control. $200 \times$ magnification, bar $=100$ $\mu \mathrm{m}$.

\subsection{Cell Viability}

The mitochondrial succinate dehydrogenase in viable cells can react with MTT and a typical blue-violet endproduct is formed; this can be used to assess cell growth and proliferation viability. Figure 5 shows that the number of cells on all the films increased as a function of culture time and then declined on the eleventh day. The decrease of cell viability was mainly due to cell apoptosis after culturing for 9 days, which was consistent with the results of previous studies [28]. The crosslinking agent greatly influenced cell viability. For the genipin and ethanol groups, cells grew well. Moreover, the number of viable cells on genipin and glutaraldehyde crosslinked SF films has significant differences, the genipin group bore more cells than the glutaraldehyde group after culture for $3,5,7,9$, and 11 days. The cells on the PEGDE group also had high proliferation vitality, but did not proliferate so well as that on the genipin group.

\subsection{Cell Metabolic Activity}

Figure 6 shows the total protein content of L929 cells after cultured on SF films for 4,6 , and 8 days. The total protein content of the cells on each sample increased significantly with culture time, indicating that all materials can support cell growth, metabolism and gene expression. After culturing for 8 days, the genipin and ethanol-processed groups had similar protein content, higher than 


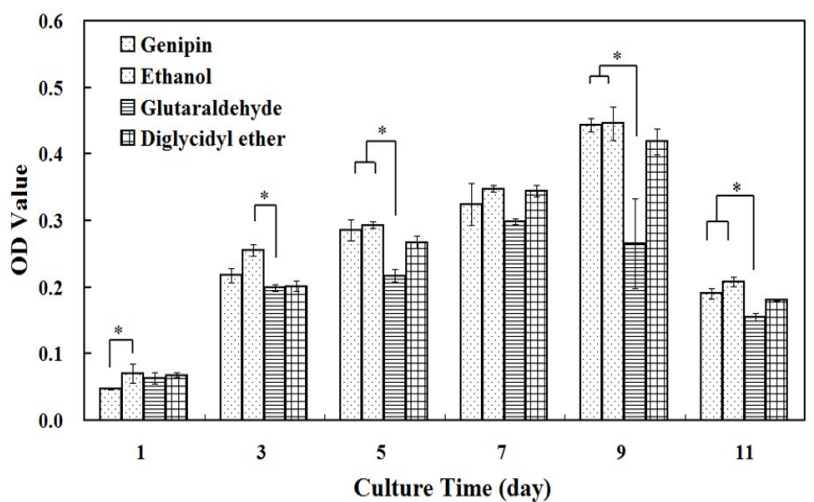

Figure 5. MTT assay after L929 cells cultured on SF films crosslinked by genipin, glutaraldehyde, PEGDE and processed by ethanol for $1,3,5,7,9$, and 11 days. "means significant difference between two groups.

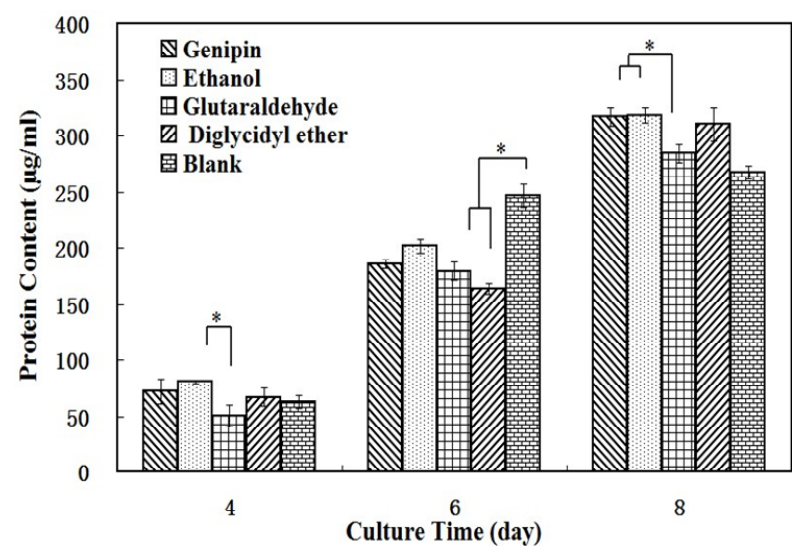

Figure 6. Total amount of protein expressed in L929 cells cultured on SF films crosslinked by genipin, glutaraldehyde, PEGDE and processed by ethanol for 4, 6, and 8 days. "means significant difference between two groups.

the glutaraldehyde group, and there was significantly difference between them. These results are consistent with the MTT assay.

\subsection{Cell Death and Apoptosis}

Figure 7 shows the analysis of cell apoptosis using flow cytometry after exposure to various SF films for 3 days. The red points in 1,2,3, and 4 quadrants in each picture represented injured cells, non-viable apoptotic and necrotic cells, live cells, viable apoptotic cells respectively. For quantitative analysis, the percentage of apoptosis cells and dead cells on these films obtained from the histogram (Figure 7) was shown in Table 3. Cells on the tissue-culture plate surfaces were used as the blank control. There was no statistically significant difference in the apoptotic index among the blank control, genipin, PEGDE and ethanol-treated groups. The glutaraldehyde group had a significantly higher apoptosis and death rate than other groups, while the genipin group had the lowest

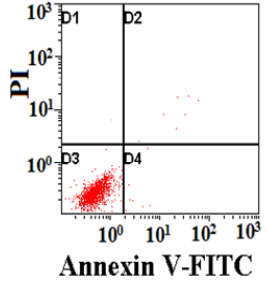

(a)

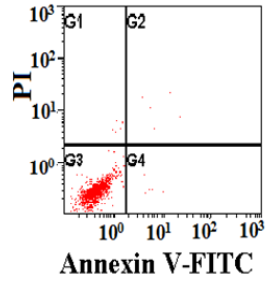

(b)

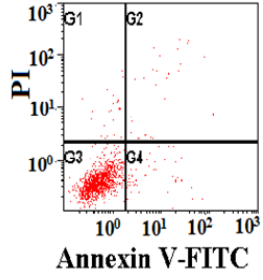

(c)

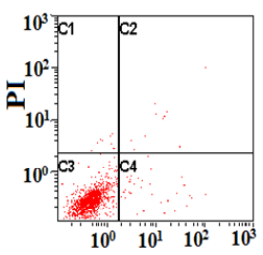

Annexin V-FITC

(d)

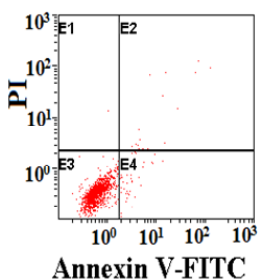

(e)
Figure 7. Flow cytometry showing cell apoptosis on SF films: (a) genipin-crosslinked, (b) ethanol-processed, (c) glutaraldehyde-crosslinked, (d) PEGDE-crosslinked, (e) control.

Table 3. Apoptotic index of L929 cells exposed to different films for 3 days. Data are shown as arithmetic mean \pm standard deviation $(n=4)$; " means significant difference between sample and control $(P<0.05)$.

\begin{tabular}{ccc}
\hline SF films & Apoptosis rate (\%) & Death rate (\%) \\
\hline Genipin-crosslinked & $1.30 \pm 0.10$ & $1.00 \pm 0.20$ \\
Ethanol-treated & $1.57 \pm 0.12$ & $0.73 \pm 0.21^{*}$ \\
Glutaraldehyde-crosslinked & $7.43 \pm 2.13^{*}$ & $2.53 \pm 0.59$ \\
PEGDE-crosslinked & $3.23 \pm 1.19$ & $1.80 \pm 0.56$ \\
Blank & $3.33 \pm 0.3$ & $1.67 \pm 0.75$ \\
\hline
\end{tabular}

apoptosis rate.

If an additive has a particular genetic toxicity, it will damage the DNA in cells, and the apoptosis mechanism will start to induce cell apoptosis when the damage cannot be repaired. These results indicated that the use of genipin did not cause apoptosis in L929 cells, while glutaraldehyde had the highest genetic toxicity.

\subsection{Cell Cycle}

An intact cell cycle includes interphase and mitosis phase (M), the interphase can be divided into 4 steps: $\mathrm{G}_{0}$ (stationary phase), $\mathrm{G}_{1}$ (presynthetic phase), $\mathrm{S}$ (synthetic phase) and $\mathrm{G}_{2}$ (postsynthetic phase). Cells proliferate in an orderly and programmed manner of $\mathrm{G}_{0}-\mathrm{G}_{1}-\mathrm{S}-\mathrm{G}_{2}-\mathrm{M}$.

Figure 8 shows the cell cycle analysis results of L929 cells cultured on different films for 3 days. The DNA histograms are cell numbers (y axis) against DNA content ( $\mathrm{x}$ axis), the blue areas in each picture represent cells in $\mathrm{G}_{0} /$ (or) $\mathrm{G}_{1}$ and $\mathrm{G}_{2} /$ (or) $M$ phases successively and the red area represent cells in $\mathrm{S}$ phase. To analyze the cell 
numbers in each cell-cycle more intuitively, the distributions of cells in different cell-cycle phases were analyzed from the DNA histogram using multi-option cell-cycle fitting software and the percentage of cells in the $G_{0} / G_{1}$, $\mathrm{S}$, and $\mathrm{G}_{2} / \mathrm{M}$ phases for each sample are given in Table 4.

Cells in $\mathrm{G}_{0} / \mathrm{G}_{1}$ phases have the DNA content of diploid cells $(2 \mathrm{~N})$ and start to synthesize RNA and protein, $\mathrm{S}$ phase is the main phase to synthesize DNA and cells in $\mathrm{G}_{2} / \mathrm{M}$ phases continue to synthesize RNA and protein and have the DNA content of tetraploid cells $(4 \mathrm{~N})$. There
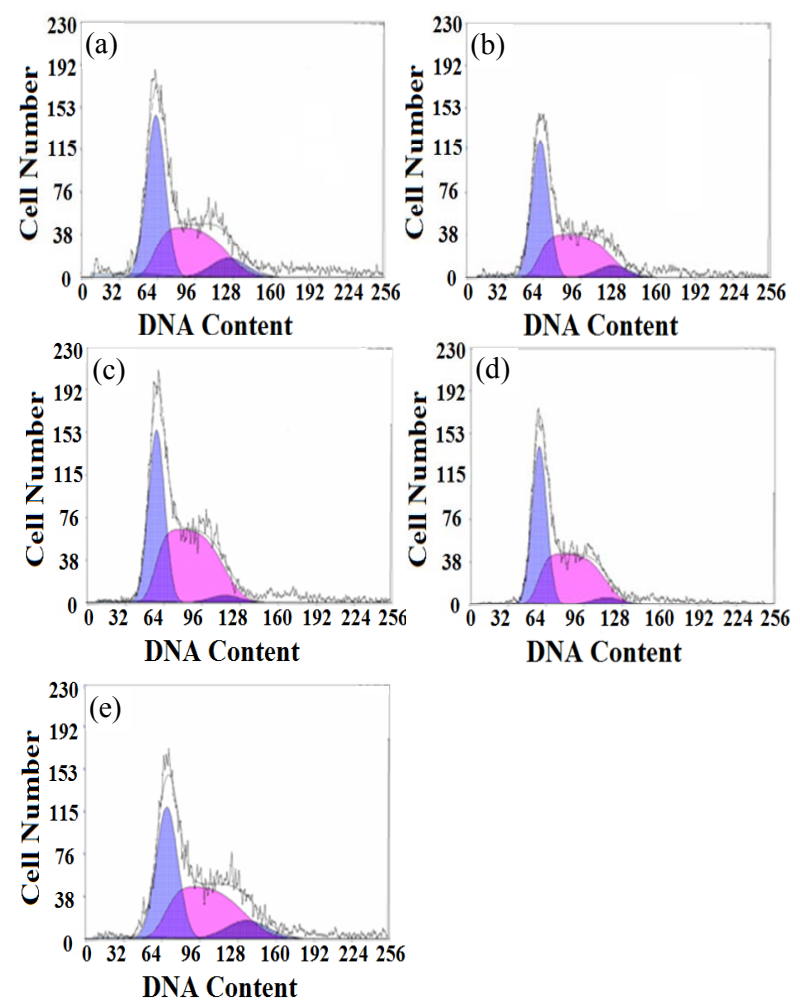

Figure 8. Cell cycle analysis results of L929 cells cultured on different SF films for 3 days: (a) genipin-crosslinked, (b) ethanol-processed, (c) glutaraldehyde-crosslinked, (d) PEGDE-crosslinked, (e) control.

Table 4. Flow cytometric analysis of the percentage of each stage in the cell cycle, after exposure to different films for 3 days. Data are shown as arithmetic means \pm standard deviation $(n=4)$. "means significant differences between the sample group and the blank group $(\mathrm{P}<0.05)$.

\begin{tabular}{cccc}
\hline SF films & $\mathrm{G}_{0} / \mathrm{G}_{1}(\%)$ & $\mathrm{S}(\%)$ & $\mathrm{G}_{2} / \mathrm{M}(\%)$ \\
\hline Genipin-crosslinked & $45.84 \pm 0.36^{*}$ & $43.27 \pm 0.23^{*}$ & $10.89 \pm 0.59$ \\
Ethanol-treated & $44.32 \pm 0.86$ & $47.89 \pm 1.52$ & $7.76 \pm 0.73^{*}$ \\
$\begin{array}{c}\text { Glutaraldehyde- } \\
\text { crosslinked }\end{array}$ & $40.95 \pm 1.45$ & $55.63 \pm 1.50^{*}$ & $3.43 \pm 0.07^{*}$ \\
PEGDE-crosslinked & $42.06 \pm 2.10$ & $53.23 \pm 1.76^{*}$ & $4.70 \pm 0.86^{*}$ \\
Blank & $42.89 \pm 1.17$ & $46.46 \pm 0.59$ & $10.65 \pm 0.66$ \\
\hline
\end{tabular}

were more cells in the $G_{0} / G_{1}$ and $G_{2} / M$ phases for the genipin group than for the other groups. The percentage of cells in the $G_{2} / M$ phase in the genipin group was similar to the blank control and had significant difference with other groups. The glutaraldehyde group exhibited the most obvious lag in $\mathrm{S}$ phase and fewer cells entered the $\mathrm{G}_{2} / \mathrm{M}$ phase normally; PEDGE group also showed low mitotic figures of about $4.7 \%$ and a high $\mathrm{S}$ percentage of about $53 \%$. These results implied that the glutaraldehyde group and PEGDE group blocked proliferation of L929 cells by arresting the cells in the S phase of the cell cycle and had potential genetic toxicity. No noticeable cell-cycle changes were observed in genipin group compared with the blank control, indicating normal patterns without any visible cell cycle arrest. Thus the genipin-crosslinked SF film could maintain a normal cell cycle and had little effect on cell-cycle progression.

Through the chemical reaction between genipin and the free amino group on the side chains of SF macromolecules, inter-molecular and intra-molecular covalent bonds were formed in SF (Figures 1 and 2). Amino acid analysis results demonstrated that the content of lysine and tyrosine in SF decreased after genipin crosslinking (Table 2). The weight loss rate results showed that the film achieved a more stable performance in water. In addition, the FTIR spectra showed that there had been rearrangement of the macromolecular segments in the film and the proportion of $\beta$-sheet conformation increased significantly, showing that genipin could also induce the SF molecular formation to translate from random coil or/and $\alpha$-helix configuration to $\beta$-sheet. This change further improved the stability of the film in water as well as endowing the film with a higher ability to resist biodegradation and postpone its collapse time as a scaffold for tissue engineering. After culturing L929 cells on different films, the genipincrosslinked SF films showed a similar affinity to cells as ethanol-processed ones, and a higher bioactivity in promoting cell proliferation, inhibition of cell apoptosis, and maintenance of normal cell cycle compared with glutaraldehyde and PEGDE crosslinked SF films.

\section{Conclusion}

Silk fibroin film was crosslinked effectively by genipin. FTIR spectroscopy and amino acid analysis proved that genipin could react with the $-\mathrm{NH}_{2}$ groups on the side chains of SF macromolecules and to form inter- and intra-molecular covalent bonds. Moreover, genipin induced the conformational translation of the SF film from random coil and/or $\alpha$-helix to $\beta$-sheet, and the water resistance was improved significantly. Genipin-crosslinked SF films exhibited higher cell viability and metabolic activity for L929 cells than films crosslinked with glutaraldehyde and PEGDE. The genipin-crosslinked SF film could maintain a normal cell cycle and had the lowest 
cell apoptosis among all groups. These results showed the safety and high efficiency of genipin as a crosslinking agent in bioactive silk-based materials.

\section{Acknowledgements}

This work was supported by the National Nature Science Foundation of China (30970714), the College Natural Science Research Project of Jiangsu Province (12KJA430003), the Key Program in Medical Science Research of Military (No. BWS11C061) and the Priority Academic Program Development of Jiangsu Higher Education Institutions.

\section{REFERENCES}

[1] N. Guziewicz, A. Best, B. P. Ramirez and D. L. Kaplan, "Lyophilized Silk Fibroin Hydrogels for the Sustained Local Delivery of Therapeutic Monoclonal Antibodies," Biomaterials, Vol. 32, No. 17, 2011, pp. 2642-2650. doi:10.1016/j.biomaterials.2010.12.023

[2] D. G. Harkin, K. A. George, P. W. Madden, I. R. Schwab, D. W. Hutmacher and T. V. Chirila, "Silk Fibroin in Ocular Tissue Reconstruction," Biomaterials, Vol. 32, No. 10, 2011, pp. 2445-2458. doi:10.1016/j.biomaterials.2010.12.041

[3] H. Zhu, J. Y. Shen, X. X. Feng, H. P. Zhang, Y. H. Guo and J. Y. Chen, "Fabrication and Characterization of Bioactive Silk Fibroin/Wollastonite Composite Scaffolds," Materials Science and Engineering C, Vol. 30, No. 1, 2010, pp. 132-140. doi:10.1016/j.msec.2009.09.009

[4] Q. Zhang, Y. H. Zhao, S. Q. Yan, Y. M. Yang, H. J. Zhao, M. Z. Li, S. Z. Lu and D. L. Kaplan, "Preparation of Uniaxial Multichannel Silk Fibroin Scaffolds for Guiding Primary Neurons," Acta Biomaterialia, Vol. 8, No. 7, 2012, pp. 2628-2638. doi:10.1016/j.actbio.2012.03.033

[5] B. D. Lawrence, J. K. Marchant, M. A. Pindrus, F. G. Omenetto and D. L. Kaplan, "Silk Film Biomaterials for Cornea Tissue Engineering," Biomaterials, Vol. 30, No. 7, 2009, pp. 1299-1308.

doi:10.1016/j.biomaterials.2008.11.018

[6] E. Servoli, D. Maniglio, A. Motta, R. Predazzer and C. Migliaresi, "Surface Properties of Silk Fibroin Films and Their Interaction with Fibroblasts," Macromolecular Bioscience, Vol. 5, No. 12, 2005, pp. 1175-1183. doi:10.1002/mabi.200500137

[7] G. M. Nogueira, A. C. D. Rodas, C. A. P. Leite, C. Giles, O. Z. Higa, B. Polakiewicz and M. M. Beppu, "Preparation and Characterization of Ethanol-Treated Silk Fibroin Dense Membranes for Biomaterials Application Using Waste Silk Fibers as Raw Material," Bioresource Technology, Vol. 101, No. 21, 2010, pp. 8446-8451. doi:10.1016/j.biortech.2010.06.064

[8] M. Z. Li, W. Tao, S. Z. Lu and S. Kuga, "Compliant Film of Regenerated Antheraea pernyi Silk Fibroin by Chemical Crosslinking," International Journal of Biological Macromolecules, Vol. 32, No. 3-5, 2003, pp. 159-163. doi:10.1016/S0141-8130(03)00049-7
[9] L. Jeong, K. Y. Lee, J. W. Liu and W. H. Park, "Time-Resolved Structural Investigation of Regenerated Silk Fibroin Nanofibers Treated with Solvent Vapor," International Journal of Biological Macromolecules, Vol. 38, No. 2, 2006, pp. 140-144. doi:10.1016/j.ijbiomac.2006.02.009

[10] S. S. Deveci and G. Basal, "Preparation of PCM Microcapsules by Complex Coacervation of Silk Fibroin and Chitosan," Colloid and Polymer Science, Vol. 287, No. 12, 2009, pp. 1455-1467. doi:10.1007/s00396-009-2115-Z

[11] H. S. Mansur, E. S. Costa, A. A. P. Mansur, E. F. Barbosastancioli, "Cytocompatibility Evaluation in Cell-Culture Systems of Chemically Crosslinked Chitosan/PVA Hydrogels," Materials Science and Engineering C, Vol. 29, No. 5, 2009, pp. 1574-1583. doi:10.1016/j.msec.2008.12.012

[12] J. Y. Lai and Y. T. Li, "Evaluation of Cross-Linked Gelatin Membranes as Delivery Carriers for Retinal Sheets," Materials Science and Engineering C, Vol. 30, No. 5, 2010, pp. 677-685. doi:10.1016/j.msec.2010.02.024

[13] P. Moonsri, R. Watanesk, S. Watanesk, H. Niamsup and R. L. Deming, "Fibroin Membrane Preparation and Stabilization by Polyethylene Glycol Diglycidyl Ether," Journal of Applied Polymer Science, Vol. 108, No. 3, 2008, pp. 1402-1406. doi:10.1002/app.27528

[14] J. Y. Lai, "Biocompatibility of Chemically Cross-Linked Gelatin Hydrogels for Ophthalmic Use," Journal of Materials Science in Medicine, Vol. 21, No. 6, 2010, pp. 1899-1911.

[15] R. A. A. Muzzarelli, "Genipin-Crosslinked Chitosan Hydrogels as Biomedical and Pharmaceutical Aids," Carbohydrate Polymers, Vol. 77, No. 1, 2009, pp. 1-9. doi:10.1016/j.carbpol.2009.01.016

[16] K. Rinki and P. K. Dutta, "Physicochemical and Biological Activity Study of Genipin-Crosslinked Chitosan Scaffolds Prepared by Using Supercritical Carbon Dioxide for Tissue Engineering Applications," International Journal of Biological Macromolecules, Vol. 46, No. 2, 2010, pp. 261-266. doi:10.1016/j.ijbiomac.2009.12.009

[17] R. Meena, K. Prasad and A. K. Siddhanta, "Development of a Stable Hydrogel Network Based on Agar-Kappa-Carrageenan Blend Cross-Linked with Genipin," Food Hydrocolloids, Vol. 23, No. 2, 2009, pp. 497-509.

doi:10.1016/j.foodhyd.2008.03.008

[18] C. T. Turo, P. Gentile, S. Saracino, V. Chiono, V. K. Nandagiri, G. Muzio, R.A. Canuto and G. Ciardelli, "Comparative Analysis of Gelatin Scaffolds Crosslinked by Genipin and Silane Coupling Agent," International Journal of Biological Macromolecules, Vol. 49, No. 4, 2011, pp. 700-706. doi:10.1016/j.ijbiomac.2011.07.002

[19] S. M. Lien, W. T. Li and T. J. Huang, "Genipin-Crosslinked Gelatin Scaffolds for Articular Cartilage Tissue Engineering with a Novel Crosslinking Method," Materials Science and Engineering C, Vol. 28, No. 1, 2008, pp. 36-43.

[20] L. P. Yan, Y. J. Wang, L. Ren, G. Wu, S. G. Caridade, J. B. Fan, L. Y. Wang, P. H. Ji, J. M. Oliveira, J. T. Oliveira, J. F. Mano and R. L. Reia, "Genipin-Cross-Linked Collagen/Chitosan Biomimetic Scaffolds for Articular Cartilage Tissue Engineering Applications," Journal of Biomedical 
Materials Research Part A, Vol. 95A, No. 2, 2010, pp. 465-475. doi:10.1002/jbm.a.32869

[21] J. X. Zhu, Y. Xiong, C. G. Zeng, N. Qiang, D. P. Quan and J. Wan, "Elastic Chitosan Conduits with Multiple Channels and Well Defined Microstructure," International Journal of Biological Macromolecules, Vol. 51, No. 1-2, 2012, pp. 105-112. doi:10.1016/j.ijbiomac.2012.04.022

[22] K. Madhavan, D. Belchenko, A. Motta and W. Tan, "Evaluation of Composition and Crosslinking Effects on Collagen-Based Composite Constructs," Acta Biomaterialia, Vol. 6, No. 4, 2010, pp. 1413-1422. doi:10.1016/j.actbio.2009.09.028

[23] Y. C. Yang, C. C. Shen, T. B. Huang, S. H. Chang, H. C. Cheng and B. S. Liu, "Characteristics and Biocompatibility of a Biodegradable Genipin-Cross-Linked Gelatin $/ \beta$ Tricalcium Phosphate Reinforced Nerve Guide Conduit," Journal of Biomedical Materials Research Part B, Vol. 95B, No. 1, 2010, pp. 207-217. doi:10.1002/jbm.b.31705

[24] C. Wang, T. T. Lau, W. L. Loh, K. Su and D. A. Wang, "Cytocompatibility Study of a Natural Biomaterial Crosslinker-Genipin with Therapeutic Model Cells," Journal of Biomedical Materials Research Part B, Vol. 97, No. 1, 2011, pp. 58-65. doi:10.1002/jbm.b.31786

[25] M. Z. Li, C. S. Zhang, S. Z. Lu, Z. Y. Wu and H. J. Wu, "Study on Porous Silk Fibroin Materials: 3. Influence of Repeated Freeze-Thawing on the Structure and Properties of Porous Silk Fibroin Materials," Polymers for Advanced Technologies, Vol. 13, No. 8, 2002, pp. 605-610. doi:10.1002/pat.159

[26] Q. Lu, X. Hu, X. Q. Wang, J. A. Kluge, S. Z. Lu, P. Cebe and D. L. Kaplan, "Water-Insoluble Silk Films with Silk I Structure," Acta Biomaterialia, Vol. 6, No. 4, 2010, pp. 1380-1387. doi:10.1016/j.actbio.2009.10.041

[27] R. E. Marsh, R. B. Corey and L. Pauling, "An Investigation of the Structure of Silk Fibroin," Biochimica et Biophysica Acta, Vol. 16, 1955, pp. 1-34.

[28] Z. Gou, J. Chang, W. Y. Zhai and J. Y. Wang, "Study on the Self-Setting Property and the in Vitro Bioactivity of $\beta-\mathrm{Ca}_{2} \mathrm{SiO}_{4}$," Journal of Biomedical Materials Research Part B, Vol. 73, No. 2, 2005, pp. 244-251. 